\title{
PRESENTACIÓN
}

\section{CARTOGRAFÍAS REFLEXIVAS: GÉNERO, DISCURSOS Y CONTINGENCIAS}

\author{
Carmen Marina Barreto Vargas \\ Universidad de La Laguna \\ cbarreto@ull.edu.es
}

En este monográfico de la revista Atlántida se ofrece un análisis amplio de las relaciones dinámicas entre género, sexualidad y cuerpo. Desde una perspectiva feminista y un enfoque transnacional, se abordan distintos temas de actualidad y eventos globales recientes fomentando una discusión altamente reveladora. La selección realizada ha respondido a un triple objetivo. En primer lugar, como un acercamiento a las temáticas, las líneas de investigación y los debates desarrollados en las últimas décadas; en segundo lugar, reflejar la diversidad de planteamientos metodológicos, teóricos e interpretativos; $y$, por último, esbozar algunos itinerarios de investigación y reflexión sobre el tema.

Cuando se cumplen cincuenta años del mayo del 68, de la guerra de Vietnam, las revueltas francesas, la primavera checoslovaca y el octubre mexicano y, además, en el contexto actual, donde los abusos y vulneración de los derechos a mujeres, comunidad LGTBI+, negros, desclasados y migrantes se consideran como parte de la normalidad por ser consuetudinarios, este monográfico cobra sentido y justifica su publicación. Después de que saltaran a los titulares internacionales las denuncias por abusos sexuales y violación del productor de Hollywood Harvey Weinstein, las orgías del fotógrafo Terry Richardson, creador en los años noventa de la imagen de la «heroin chic» (mujeres ultradelgadas con una estética porno de los ańos setenta), o personajes conocidos del mundo del cine como Kevin Spacey, Brett Ratner y Bill Cosby utilizan su posición de poder para cometer abusos sexuales, la violencia sexual se ha convertido en un tema de intenso escrutinio de los medios de comunicación, sobre todo gracias a la valentía de las víctimas que deciden contar sus historias y experiencias. En Estados Unidos, dimiten también por acoso sexual el senador demócrata Al Franken, aspirante a las elecciones presidenciales de 2020, y el congresista demócrata John Conyers, el legislador más veterano de la Cámara de Representantes. La valentía y desafío de las mujeres queda de manifiesto en movimientos como \#MéToo, que ha servido para que todas las mujeres el mundo cuenten en la Red que han sido víctimas de agresiones sexuales. Desafortunadamente, las esferas jurídicas a menudo se hacen eco de los informes de violación, de manera que en numerosas

DOI: http://doi.org/10.25145/j.atlantid.2018.09.001

Revista Atlántida, 9; diciembre 2018, pp. 9-28; ISSN: e-2530-853X 
ocasiones ponen más énfasis en la responsabilidad de la víctima que en dictar una sentencia justa, institucionalizando así el abuso y la violación sexual. Es el caso de la violación en grupo de la Manada, que se produjo en los sanfermines de 2016 en Pamplona. Toda esta violencia y todas las vulneraciones contra las mujeres han recibido una respuesta internacional el $8 \mathrm{M}$ con la huelga feminista que, entendida como una forma de radicalidad y metáfora de resistencia, paró a gran parte del planeta. En cualquiera de estos ejemplos podemos observar cómo las políticas de género no protegen a las mujeres que siguen luchando sin protección contra esterilizaciones no deseadas, vientres de alquiler, mutilación genital, prostitución forzada, pornografía, matrimonios concertados, etc. Todas estas posiciones de desventaja necesitan del feminismo y de la igualdad y se necesita saber que ambas son irreversibles.

Desde mi punto de vista, el común denominador de la condición feminista es la idea de que en vez de entender el género y la sexualidad como reinos universales de la diferencia «natural», hay que analizar: a) cómo se materializan diferentes prácticas culturales dentro de los campos de poder, para entender cómo el género y la sexualidad son dominios que articulan los discursos económicos, artísticos, sobre el deseo, el cuerpo o el deporte dentro de estructuras contingentes e históricamente determinadas; $\mathrm{y} b$ ) ver hasta qué punto las categorías de lo natural dado y lo cultural construido en el binarismo de género están siendo desplazadas por los efectos de los activismos y los avances científicos y tecnológicos. Esto implica que tenemos que aprender a pensar de manera diversa en nosotros mismos, lo que llevaría a reconsiderar de manera crítica y creativa una teoría de los modelos de subjetividad alternativos ya no sexualizados, racializados y naturalizados sino más bien posthumanizados, siguiendo las propuestas de Braidotti (2015) para una nueva era. También podríamos seguir la propuesta del cíborg diseñado por Haraway (1995) para ayudarnos a pensar fuera del laberinto dualista.

El movimiento feminista se caracteriza por ser heterogéneo (igualitaristas, diferencialistas, materialistas, marxistas, socialistas, psicoanalíticas, nacionalistas, liberales, ecofeministas, radicales, posthumanistas), no deja de reinventarse continuamente y cada vez más está formado por los movimientos reivindicativos de las minorías sexuales (gay, queer, trans, crip, bolleras, tomboys, butch, marikas, etc.). De hecho, una de las innovaciones que han tenido lugar en las últimas dos décadas en relación con las expresiones utilizadas para marcar el género y el sexo no normativos ha sido el uso coloquial de un lenguaje que se utiliza para nombrar corporalidades diferentes. Lo que pone en crisis el discurso autoritario y disciplinario del período médico/psiquiátrico, que se encargaba de nombrar el complejo campo de las sexualidades, el género y las orientaciones sexuales. $\mathrm{Y}$, aunque las formas coloquiales de expresión y definición no tienen por qué ser menos reguladoras o estar menos comprometidas con las normas que otros sistemas de clasificación, sí ponen de relieve hasta qué punto los estudios sobre el sexo, género, cuerpo y política son saberes polémicos, conflictivos e incómodos para la cultura mainstream. Lo que sí me parece interesante resaltar de todo ello es el hecho de que este lenguaje, y nuevas teorías son capaces de resquebrajar los hábitos preestablecidos sobre las relaciones sexo-género-poder, provocando deliberadamente reacciones imaginarias y emocionales nuevas sobre la identidad, a pesar incluso de las diferencias y hostilidades epistemológicas y políti- 
cas entre el movimiento feminista, el feminismo lésbico y la homosexualidad gay. Apelando quizás, como propone Angela Davis, a un feminismo amplio, generoso, total que sea capaz de luchar contra toda desigualdad más allá de los géneros.

Esta situación puede ser valorada como una dificultad para diseñar idearios políticos comunes que persigan las reivindicaciones feministas y la igualdad de género. $\mathrm{O}$, por el contrario, como un conjunto de fuerzas que no estarían tan interesadas en centrar su lucha en la liberación de las mujeres como en desmantelar los dispositivos políticos que producen las diferencias de género, raza, clase y sexualidad, haciendo así del feminismo una plataforma performativa y política de invención de un futuro común del que participan tanto mujeres como grupos sexuales minoritarios. O, por último, como plantea Halberstam (2018), esta discusión entre sexualidad, género y poder más bien obedece a un fracaso que, paradójicamente, tendríamos que entender como un tipo diferente de éxito capaz de generar una nueva lógica antinormativa, anticapitalista y antidisciplinaria.

En cualquier caso, en estos tiempos convulsos, dislocados y trastornados, el feminismo sigue siendo un espacio de esperanza, de coraje y de empeño colectivo. Los estudios feministas, cada vez más extendidos, han hecho también crecer proporcionalmente la cantidad de feministas provenientes del ámbito de las ciencias sociales y humanas. En toda esta producción es difícil encontrar estudios en los que no se aluda, explícita o implícitamente, a Foucault y Butler o donde estos no sean reivindicados como los inspiradores de las nuevas teorías críticas del feminismo. Ambos autores reivindican el punto de vista de las minorías sexuales y denuncian como abusivos e intolerantes los regímenes políticos, jurídicos y médicos que los han definido como anormales, abyectos o monstruosos. Los sujetos pueden oponer resistencia a toda la identidad sexual que imponen las normas. Foucault subraya que la sexualidad es un dispositivo de poder típico de la modernidad, la entiende como un complejo entramado de convenciones, normas, prácticas, conocimientos que tienen como fin gobernar los cuerpos, comportamientos y subjetividades mediante la definición y la imposición de identidades sexuales y raciales que operan bajo un régimen biopolítico. A su vez, Butler propone la teoría de la performatividad para romper con el control que ejercen las normas sobre los cuerpos de los sujetos con sexualidades minoritarias. El objetivo es conseguir que las minorías sexuales y de género sean más factibles, menos traumáticas, más vivibles, tanto en aquellos cuerpos que no se ajustan al género establecido como también en los que se ajustan demasiado bien con un alto coste para ellos. Aceptar las identidades oprimidas (raciales y sexuales) equivale a aceptar los guiones dominantes que el poder ha inventado sobre ellas. Tanto Foucault como Butler, Derrida o Freud insisten en que todas las formas de denominación social son un acto alienante porque provienen de un poder siempre pernicioso. Todas estas consideraciones teóricas están presentes en los debates sobre género y, de manera muy significativa, en las reconsideraciones teóricas de la filosofía, la tecnología y el arte. 
En el texto de Lourdes Méndez, «Una posición de dentro, pero fuera: las artistas y sus obras en el campo del arte», se ponen de manifiesto las contradicciones ideológicas del campo del arte a la hora de reconocer la obra y la trayectoria profesional de las artistas. Mediante la dicotomía dentro-fuera y los análisis antropológicos feministas del campo del arte, Lourdes Méndez establece unas provocativas observaciones acerca del papel de las artistas mujeres en el ámbito artístico. Analiza y contextualiza también qué acontece y cómo funcionan los circuitos del arte en el Estado español de las Autonomías, apuntando cómo todavía en 2018, según datos cualitativos y cuantitativos, los análisis demuestran que las artistas están infrarrepresentadas en todos los ámbitos que les permitirían consolidarse dentro del contexto del arte contemporáneo. Las artistas, según reseńa la autora, siguen estando dentro pero fuera del campo del arte tal y como se refleja en la inferioridad numérica de las artistas en la asignación de premios y en la programación expositiva de las instituciones públicas de arte. La idea del texto se articula en torno a la carga de prejuicios que rodean las obras de las artistas mujeres y al hecho de que el arte esté estructurado en base a las variables de sexo, raza/etnicidad y clase a través de las cuales se organizan desigualdades y jerarquías que afectan al sujeto artista como a la percepción estética y evaluación crítica de sus obras. Directores de museos, galerías o críticos de arte siguen esforzándose en mantener, por ejemplo, que lo importante es la obra y no la autoría, que los hombres económicamente más fuertes compran la obra de los hombres, que las mujeres desisten más rápido en sus carreras, obviando el papel que el sexo juega en todo este contexto.

Queda de manifiesto que ser mujer artista sigue siendo un tema de género ligado a las limitaciones de oportunidades que tienen las mujeres, para expresarse a través de actos creativos y de producción artística. La carrera artística es todavía hoy, como ha presentado Bain, un mundo de hombres. Y todo ello, a pesar de que en el ámbito universitario hay más mujeres matriculadas en las Facultades de Arte que varones incluyendo los campus universitarios de EE. UU. Por el contrario, el número de docentes en estas instituciones académicas es altamente masculino (Bain, 2004; 2005; 2007). Podemos, pues, hablar de un fenómeno transnacional.

El talento, la habilidad y la capacidad de las artistas mujeres no se valoran de igual manera que se hace con los artistas varones, motivo por el cual también sus obras están peor pagadas que las de ellos. Si a esto se le suma que galeristas, comisarios, directores de museos, coleccionistas y muchos críticos de arte dan más promoción, publicidad y cobertura a los artistas varones, son innegables las repercusiones negativas y las deformaciones que esto tiene en la carrera y en la visibilización de las artistas mujeres. Si se sigue argumentando esta realidad con discursos como que las mujeres compaginan su arte con los cuidados a la familia; que tienen menos aspiraciones de lucro que los artistas varones; que son más dependientes, emocionales e inseguras (Pollock, 1980); que el arte no es una cuestión de cuotas; o que las artistas mujeres son más organizadas que los artistas varones, a los que se les considera más creativos por estar menos sujetos a las reglas, reforzando así un legado de asociaciones entre masculinidad, creatividad y cierto reconocimiento esteta (Nixon, 2003), como 
si lo artístico fuera una prerrogativa masculina, podríamos mantener que la condición del arte seguirá siendo un territorio históricamente negado a las mujeres y una parcela incómoda de la representación. Por otro lado, no resulta difícil advertir que toda esta línea discursiva se volvería obsoleta desde el momento en que las mujeres tengan el control real sobre las producciones y las industrias culturales y artísticas.

Por estas razones, a mediados de los ańos sesenta del siglo pasado, el arte feminista hace una crítica a la razón patriarcal y a la representación, proponiendo un análisis de los orígenes de la discriminación de género, la reivindicación de la lucha contra tal discriminación, la recuperación de las artistas mujeres olvidadas y no reconocidas socialmente, la crítica de las normas y valores establecidos por una historia del arte masculina, la revisión de las imágenes de las mujeres en el arte, la perspectiva feminista en el arte, la reivindicación de la artesanía como producción artística y, en algunos casos, la afirmación de una sensibilidad artística exclusiva y discernible. En definitiva, como plantea Pollock, había que refutar las mentiras sobre la inexistencia de artistas mujeres o, en el caso de las que han sido admitidas, la idea de que eran de segundo orden, y que su indiferencia se debe a la sumisión generalizada a una indeleble feminidad, siempre planteada como una incapacidad incuestionable para crear arte (2003: 119). Con estas estrategias feministas, las artistas mujeres se enfrentaban a una visión moderna del arte sin sexo. No debemos olvidar que en un contexto de lucha cultura en los primeros años sesenta, el modernismo y el feminismo chocan frontalmente como dos paradigmas históricos, donde el primero se expone a su decadencia a la vez que se hace visible la presencia pública de las artistas mujeres en el arte tradicionalmente denominado «elevado».

Tal y como ha descrito Lippard, el arte feminista tiene como objetivo cambiar el carácter del arte. Constituye un sistema de valores, una estrategia revolucionaria, una forma de vida que, como el dadaísmo o el surrealismo, ha continuado dominando todos los estilos y movimientos desde entonces. Cabe resaltar la importancia táctica-política que le atribuye al género, entendido como un proyecto amplio encaminado a reenlazar las prácticas artísticas con las comunidades y los objetivos sociales radicalmente opuestos al elitismo institucionalizado de la canonizada cultura moderna (1980: 362-365). Estas consideraciones alentaron la necesidad y el surgimiento de un activismo político por parte de las artistas feministas, que se organizaron para afrontar el espacio público y el reconocimiento dentro del mismo de una historia propia.

Nochlin en 1971 realiza una pregunta clave en este contexto de renovados esfuerzos feministas en el arte: «¿Por qué no han existido grandes artistas mujeres?». La explicación de esta ausencia la plantea desde un punto de vista sociológico, al afirmar que las mujeres como artistas estuvieron excluidas del proceso creativo al ser rechazadas de las clases de dibujo anatómico dentro de las academias, al negarles la ambición profesional y la dedicación a la excelencia y, por último, la idea de genio era propia solo de un sexo varón capacitado para concebir grandes proyectos arquitectónicos, esculturas monumentales y formas elevadas de pintura con motivos históricos y religiosos. Todo ello impidió a las mujeres la creación de obras «mayores». Las mujeres quedaban así relegadas a las esferas «menores» del retrato, el arte gráfico, los paisajes o las naturalezas muertas, haciendo constancia de lo que se consideraba 
era propio de su "condición biológica» y del «papel doméstico» de su arte (2007). Se tomaba conciencia del proceso histórico, de las prácticas discriminatorias y las convenciones sociales, que han determinado la situación actual de las artistas mujeres y que Nochlin denomina el «mito del Gran Artista».

En el año 1985, irrumpen en la escena artística de Nueva York las «Guerrillas Girls», un grupo de mujeres que protestan contra el sexismo en el arte y la ausencia de las mujeres en los premios que se otorgan en el mundo artístico dando continuidad a la pregunta que se formuló Nochlin. En el anuncio de 1989 Cómo logran las mujeres ser más expuestas de las «Guerrillas Girls», realizado en un intenso amarillo plátano, aparece un desnudo reclinado de Ingres con la cabeza de gorila. En el texto se pregunta si las mujeres tienen que estar desnudas para entrar en el Museo Metropolitan. Y añade que solo el $5 \%$ de los artistas de la sesión moderna son mujeres, en comparación con el $85 \%$ de los desnudos. Así comienza su guerrilla para, por un lado, desafiar la exclusión de las artistas mujeres en las listas de artistas, museos, galerías, premios y reconocimientos. En segundo lugar, derrumbar y desjerarquizar el canon imperante en el arte, porque lo que se consigue reiteradamente es consagrar las ideas tradicionales sobre lo que contribuye a la "grandeza» y la «calidad» en el arte. Una «grandeza» y «calidad» que excluye siempre a las mujeres. Y, por último, se introducen los discursos de las minorías étnicas y las luchas LGTBI.

Lourdes Méndez se plantea nuevas preguntas que ponen en entredicho este credo, que, como hemos visto, no ha sido superado. Estos planteamientos, periódicamente renovados, impiden que se cuestionen los condicionantes sociales, sexuales, económicos, políticos y simbólicos que intervienen en el campo del arte, principalmente porque son los varones occidentales de nacionalidad estadounidense, alemana o británica quienes controlan en campo del arte. Por esta razón, son ellos quienes siguen reproduciendo el marco conceptual que hace difícil legitimar a las artistas, a los artistas étnicos y, por extensión, a sus obras. Además, Lourdes Méndez argumenta de manera convincente cómo las artes son jerárquicas y funcionan según el criterio y la regla masculina.

Haciendo un poco de arqueología del momento de la confrontación feminista del arte con el modo dominante de consumo del arte y su inconsciencia feminista, quisiera expresar en primer lugar que aún hoy las artistas mujeres siguen llevando la carga del pasado y, en segundo, la necesidad del feminismo de seguir desenmascarando la política sexual de los discursos y los circuitos del arte dominantes (museos, academias, galerías y mercado) para poder legitimar la obra de las artistas. La preocupación por la percepción, representación, identificación, experiencia sensual y la subjetividad difícilmente habrían ocupado el primer plano de los debates sobre arte y estética si no hubiera sido por la presencia social y política del movimiento feminista en el arte y la insistencia de las mujeres en que estas nociones demarcadas por los varones no resultan válidas para ellas. 
En 2008, en la sociedad ucraniana postsoviética aparece un movimiento de resistencia y postfeminista que luchará activamente por derrocar el sistema patriarcal heteronormativo, poniendo por delante al cuerpo. El texto «Movimento politico o gruppo performativo? Storia, obiettivi, metodi di Femen», que presenta Donatella Schmidt, nos sirve para mostrar un desafío combativo del cuerpo de las mujeres y el uso político que se hace del mismo. El cuerpo femenino se utiliza como estrategia y como arma para la protesta. La autora analiza desde un punto de vista político y performativo esta organización feminista que nació bajo una coyuntura histórica determinada que fue la denuncia contra la explotación turística sexual de las mujeres prostitutas y el intento de legalizar la prostitución en el contexto de la Eurocopa de fútbol de 2012, celebrada en Ucrania. Bajo el eslogan «Ucrania no es un burdel» comienza su lucha en un país donde la industria del sexo funciona como la comida rápida, como una especie de McDonald's, fácil y barata.

Donatella Schmidt refuerza desde el comienzo del artículo la idea de que estas protestas han puesto el foco de atención mundial en problemas como las dictaduras, la industria del sexo, las injerencias de las instituciones religiosas en la vida civil, sexual o reproductiva de la mujer moderna, que si bien en un principio se visualizaban desde Ucrania, están presentes y no resueltos en todas las sociedades gobernadas por y para los hombres. Desde este momento, en que Anna Hutsol y un grupo de estudiantes organizan unas primeras performances para atraer la atención de la prensa y el público en general, Femen no ha dejado de crecer hasta convertirse en un movimiento internacional de activistas totalmente constituidas en países como Francia, Alemania, España, Suecia, Italia, Bélgica, Países Bajos, Israel, Canadá, México, Turquía y Estados Unidos, creando redes transfronterizas. Convencidas de que la prensa, ávida de espectáculo, necesita del escándalo, el sexo y la muerte para conseguir atraer la atención, diseñan actuaciones cada vez más radicales. Donatella Schmidt está convencida de que Femen ha supuesto una oportunidad para renovar y estimular el discurso feminista y una manera de reflexionar de nuevo sobre las modalidades expresivas del cuerpo femenino, aunque deja abierta la posibilidad de que cada persona tome su posicionamiento al respecto.

Vemos como en esta ocasión, la desigualdad de género es criticada por un grupo de mujeres jóvenes con el pecho descubierto y cubierto de proclamas con las cabezas tocadas con coronas de flores y con el puño alzado. Según Femen, el cuerpo se le ha arrebatado a la mujer y ha sido objeto de explotación monstruosa. El control absoluto del cuerpo de la mujer es el principal instrumento con el que se le oprime. Sin embargo, que las mujeres tomen las riendas de su sexualidad es la clave de su liberación. Que la mujer proclame que es dueña de su propio cuerpo supone el primer paso y el más importante para que consiga la libertad. El desnudo femenino, liberado del sistema patriarcal, destruye ese sistema, es el manifiesto de nuestra lucha y el símbolo sagrado de la liberación de la mujer (Femen, 2014: 6). La táctica para conseguirlo es lo que denominan «sextremismo", es decir, la rebelión de la sexualidad femenina contra el patriarcado a través de actos políticos extremos de acción directa (Femen, 2014: 7-8). 
Así pues, el cuerpo se entiende como una metáfora por su capacidad para transformar la realidad, tal y como planteó Turner (1974), y de ahí su poder transformador. A partir de los años noventa la denuncia social y política no se concibe sino dentro de un planteamiento teórico y activista corporal. El cuerpo se erige como un referente del Body Art y de las performances. Este retorno al cuerpo, lo entiende Femen no como una noción abstracta, sino como un soporte real que se mantiene gracias a lo externo, el maquillaje y patrones estéticos que deliberadamente obedecen a los códigos de belleza patriarcales. Ponen en escena unos cuerpos estéticamente artificiosos en actitud de rebeldía. Paradójicamente, utilizan los atributos del sexismo para luchar contra el propio sexismo, convencidas de que las mujeres siempre han estado sometidas a los dictados estéticos de los varones para satisfacer sus deseos. De esta misma postura, derivan parte de las críticas que sobre el movimiento se han vertido.

Femen se considera heredero de una larga reflexión teórica del feminismo a la vez que reconocen su indignación ante una sociedad dominada por los hombres en la que las mujeres deben mantener la boca cerrada y la vagina abierta. A la vez, el feminismo de los años setenta-ochenta considera que el feminismo que defienden es ingenuo y poco elaborado teóricamente. La desnudez femenina es un arma de resistencia pacífica, pero no por ello menos temible, tal y como se refleja en el Manifiesto Femen, traducido por Irene Aragón y publicado en 2015 por Hoja de Lata Editorial. La desnudez, entendida por el movimiento como una técnica universal de protesta, ha sido ampliamente discutida y, sin lugar a dudas, ha incomodado a muchas organizaciones y sectores feministas. Se les critica el uso del desnudo como reclamo de la representación sexual femenina. No olvidemos, por otra parte, que el tema de la sexualidad ha sido arrinconado por el feminismo más institucional desde que ha ido ocupando puestos de poder. A la vez se les dice que mostrando los pechos lo que consiguen es fomentar los estereotipos sexistas. Queda claro que para unas las performances de Femen es una muestra de decadencia y frivolidad y para otras es un ejercicio de rebeldía.

Desde un primer momento, este movimiento generó desacuerdos dentro del feminismo, donde se planteaba abiertamente la posibilidad real de estar perdiendo los derechos ya conquistados por las mujeres en materia de igualdad y que se creían inalterables como la libertad sexual y la igualdad de oportunidades, conseguidas entre los años sesenta-noventa del siglo pasado. Con todo, habría que reconocerles su capacidad para cuestionarse públicamente una normatividad patriarcal que ha considerado «natural» la dominación, la exclusión, la discriminación y la violencia sobre las mujeres. Al mismo tiempo, es resaltable que, al definirse abiertamente como feministas, ponen el concepto otra vez en el centro de los debates en medio de un contexto transfeminista que lo ha relegado al poner en el centro de sus preocupaciones la discriminación, la estigmatización y desigualdad de, por ejemplo, lesbianas, gais, bolleras, butch y trans. Y, por último, reseñar la paradoja de que mientras el cuerpo desnudo de las mujeres es usado y representado por los hombres cotidianamente a través de la publicidad o el porno, situando al espectador como voyeur de lo minusvalorado, cuando son las propias mujeres quienes utilizan su cuerpo, no para satisfacer la mirada masculina, sino para representarlo como arma 
de protesta, rebelión y resistencia es cuando se convierte en un cuerpo censurable por indomesticado y delictivo.

Las mujeres, como hemos visto, tienen que radicalizarse muchas veces para poderse resituar en un continuo combate de desigualdad. Otro ejemplo de esto se pone de manifiesto en el artículo de Sarai Rodríguez titulado «Brechas de género en el mercado laboral: una mirada crítica ante el horizonte 2030». La desigualdad que sufren las mujeres en el mercado de trabajo y la brecha de género que esto implica en el acceso al empleo, salarios, pensiones, puestos de liderazgo y conciliación laboral y familiar son los temas que la autora relaciona en el texto. Se analiza la Agenda sobre Desarrollo Sostenible 2030 de Naciones Unidas para determinar cuáles son las causas de la reiterada desigualdad en el mercado de trabajo. Al mismo tiempo, propone de manera programática las medidas de acción positivas que garantizarían el empleo y los derechos laborales efectivos para las mujeres, como la racionalización de horarios y la flexibilidad del tiempo de trabajo y la corresponsabilidad en las labores de cuidados. De manera real, formal y efectiva, esto pasa por diseñar políticas de igualdad en el trabajo dado que, según la experiencia histórica, todo lo que significa un proceso de cambio en el sistema económico y financiero en el contexto de países desarrollados supone enfrentarse a un campo lleno de resistencias. El mercado de trabajo sigue siendo refractario a la igualdad, y más aún, en los puestos de trabajo y empresariales cualificados, donde la brecha de género aumenta. Esto lo demuestra el hecho de que, como expresa la autora, el tema de los derechos laborales e igualdad se ha planteado por la Organización Internacional del Trabajo en el 2013 o en la Estrategia Europea 2020 con el objetivo, en este último caso, de garantizar la tasa de empleo total del $75 \%$ para hombres y mujeres en la Unión Europea. Objetivo que dista mucho de conseguirse en Europa y en Espańa en la fecha programada.

Los hallazgos de la investigación se resumen y comparten cada cierto tiempo con datos estadísticos que en no pocas ocasiones muestran un panorama bastante desalentador, a pesar del cual resultan necesarios para crear una conciencia social que pueda encarar las contradicciones de un sistema económico que sigue resistiéndose a incorporar el talento de las mujeres a los mercados de trabajo y a los órganos de decisión de la sociedad contemporánea. Este artículo nos demuestra cómo a pesar de estar en un nuevo milenio sigue siendo un desafío la incorporación de las mujeres al mercado laboral y cómo a pesar de que la Organización Internacional del Trabajo se pronuncia a favor de crear políticas dirigidas a mejorar la calidad de esos empleos, las mujeres siguen copando altos índices de ocupación en la economía sumergida, lo que incrementa exponencialmente la brecha salarial entre hombres y mujeres.

Distintas comisiones, pactos por la igualdad, informes o la propia ONU, tal y como Sarai Rodríguez señala indicando sus normativas y compromisos, hablan de garantizar la igualdad de remuneración por trabajo de igual valor, pero no solo no se han alcanzado estos objetivos, sino que, además, de manera discriminatoria, su no consecución afecta directamente al disfrute de un sistema público de pensiones 
y prestaciones igualitario y a la independencia económica de las mujeres. Esta realidad se plantea en el artículo como una consecuencia de la histórica distribución sexual del trabajo.

El esqueleto conceptual de la economía tradicionalmente ha planteado el trabajo abnegado de las mujeres dentro del ámbito doméstico, y por lo tanto desde un principio mujeres y economía no representaba nada realmente significativo en términos de beneficios. nomía:

Como plantea Marçal, desde una perspectiva feminista y crítica de la eco-

Las actividades como criar a los niños, limpiar la casa o lavar y planchar la ropa de la familia no crean bienes tangibles que se puedan comprar, intercambiar o vender, y, por lo tanto, según los economistas del siglo xix, tampoco contribuyen a la prosperidad social. Solo lo hacían aquellas cosas que podían ser transportadas, cuya oferta era limitada, y que directa o indirectamente proporcionaban placer o evitaban el dolor. De acuerdo con esta definición, todo aquello a lo que se esperaba que se dedicaran las mujeres se volvió invisible. Los frutos de la mano de obra masculina podían ser apilados en montones y valorados monetariamente. Los resultados del trabajo de las mujeres eran intangibles. El polvo que ha sido barrido vuelve a aparecer. Las bocas que han sido alimentadas vuelven a tener hambre. Los niños, una vez dormidos, se despiertan al cabo de un rato. Después del almuerzo, es hora de lavar los platos. Después de lavar los platos, es hora de cenar. Y de nuevo es hora de lavar los platos sucios después de la cena. Las tareas del hogar son de naturaleza cíclica. Por lo tanto, el trabajo de la mujer no era una "actividad económica», sino, pura y simplemente, una extensión lógica de su naturaleza bondadosa y amorosa. Siempre iba a continuar realizando ese trabajo, que por ello no necesitaba cuantificación. Procedía de una lógica distinta a la económica. De la lógica femenina. La lógica del «otro» (2017: 40).

En la revita The Atlantic, número julio/agosto de 2012, la feminista Anne Marie Slaughter, que había ocupado un alto cargo en el Gobierno de Obama, publicó un artículo titulado "Why women still can't have it all», en el que planteaba cómo las mujeres que logran combinar con éxito (palabra que se conjuga básicamente en masculino) la maternidad y una posición de alto nivel son heroínas, ricas o trabajan por cuenta propia. Sin entrar en este momento en los debates que este artículo ha generado, la conclusión a la que llega Slaughter es que para la mayoría de las mujeres que sí trabajan en la esfera pública en puestos de trabajo de grandes compañías, corporaciones, consejos ejecutivos o en política les es imposible hacer compatibles sus trabajos con la crianza y cuidado de la prole. Ante esta situación, la sociedad actual cuestiona y culpabiliza a las propias mujeres por no anteponer sus carreras a sus familias. Por el contrario, se premia y son considerados auténticos profesionales aquellos que lo hagan, generalmente los hombres. Esto implica que las mujeres tienen que estar continuamente eligiendo, renunciando y planificando. No cabe duda de que esta brecha de género origina otra discriminación en términos de bienestar aunque haya mujeres que no quieran privarse de criar a sus hijos e hijas, otras que prefieren congelar sus óvulos y dar prioridad a su vida profesional, otras 
que renuncian simplemente a ser madres y reivindican con orgullo una vida sin descendencia, mujeres que reivindican la soltería como espacio de libertad, exactamente igual que hay mujeres partidarias y detractoras del aborto, de la prostitución, de los vientres de alquiler, mujeres que rechazan la pornografía por entender que es una forma de violación, y actrices porno que se reivindican orgullosas en política, o la empresa cinematográfica.

En cualquier caso, las mujeres necesitan tener acceso a las oportunidades económicas, la posibilidad de una independencia económica y el total control sobre sus ingresos para romper con el círculo vicioso de que las mujeres tengan que cargar con el cuidado de los hijos y las tareas domésticas. Un trabajo no remunerado que afecta a su dedicación profesional y a sus metas más ambiciosas, y que las condena a un empleo precario. En contra de lo que ha sido la historia del pensamiento económico como una ciencia mecanicista y reduccionista basada exclusivamente en los valores monetarios, habría que apostar por una economía feminista que incluya los trabajos de cuidados de las mujeres dentro de los ámbitos no monetizados de la economía, evitando así la subordinación de las mujeres a los hombres. Por otro lado, tanto en países desarrollados como en vías de desarrollo, la contribución de la fuerza laboral de las mujeres ha contribuido al desarrollo de esos países; si a esto le añadimos que las mujeres son la mitad de la población mundial, no se entiende la reticencia de los gobiernos a la hora de impulsar los cambios económicos en favor de la igualdad. Cambios que, por otra parte, solo producirían beneficios económicos y éticos.

\section{IV}

En «África en femenino: una aproximación a su(s) literatura(s)», Alba Rodríguez nos da la oportunidad de conocer la literatura femenina africana y la creatividad de numerosas autoras que están convirtiendo sus ejemplares en éxitos de venta mundial. A través de un pensamiento crítico, rechaza las ideas que han venido sosteniendo numerosos autores sobre el hecho de que la literatura africana aparece con la civilización árabe y europea. Además, más allá de la literatura de Chinua Achebe, autor considerado por muchos como el fundador de la literatura africana, y el fenómeno de repercusión internacional que ha tenido la obra de Chimamanda Ngozi Adichie, en el texto se reivindican muchas autoras africanas que mantienen un diálogo desde África, con África y con la diáspora cosmopolita de la que participan. Este interés por la literatura africana ha sido posible en gran medida por la creación de los Estudios Africanos y Literatura, que se han ido expandiendo internacionalmente entre los años cincuenta y sesenta.

Alba Rodríguez pone de relieve la importancia que han tenido en la literatura africana el carácter oral de la cultura, los jeroglíficos de la época del gran imperio egipcio, el gran número de lenguas del continente y el conjunto de etnias y géneros literarios, para trascender ideas y avatares, propios de las administraciones coloniales, que durante mucho tiempo se han vertido sobre África, negando esta realidad de complejidad y riqueza cultural. 
No podemos aquí obviar una reflexión sobre el hecho de que si esta realidad diversa e híbrida de la cultura africana la uniéramos a la pulsión obsesiva de la Modernidad y de la Ilustración de tener que clasificarlo todo con rígidas categorías, rememorando a Lévi-Strauss, como un mecanismo de sujeción y de supervisión de las poblaciones locales colonizadas, podríamos entender rápidamente las contingencias y las facilidades que los estados coloniales han tenido para negar históricamente lo que no han considerado como importante en culturas como las africanas que querían neutralizar y no preservar.

Alba Rodríguez sitúa a finales de los años sesenta los orígenes de la literatura africana escrita por las mujeres, período que siguió a la independencia y que se caracterizó por la explosión a comienzos de los años treinta del movimiento conocido como «negritud». Y que podríamos definir como un intento de resignificar el término «negro» como una toma de conciencia de la diferencia, como memoria, fidelidad y solidaridad que alimenta la resistencia y la lucha de las comunidades negras (Césaire, 2006: 87) y, a la vez, como un sentimiento nostálgico que provoca el rechazo del mundo blanco europeo en favor de la exaltación de las culturas negras vulneradas por las políticas y las administraciones colonizadoras. Un contexto de desilusión que aparece en la literatura a través de la sátira sociopolítica. Básicamente, son los hombres los que escriben y en sus obras, destaca la autora, aparece frecuentemente como eje narrativo la imagen de las mujeres. Y aparecen las mujeres no solo a través de un retrato real sino sobre todo, diría yo, como un tótem que simboliza el poder de la imagen ideal de mujer africana. Una situación que, cabe resaltar, no ayuda a subvertir el papel doméstico de las mujeres africanas sino que más bien ayuda a legitimarlo.

Por otro lado, la autora se vuelca de manera exhaustiva con la literatura africana femenina postcolonial en lenguas europeas, contextualizando social, política y económicamente los años ochenta, en los que emerge esta producción cultural. Las primeras obras realizadas por las mujeres son de esta década, sufriendo a lo largo del tiempo un doble desplazamiento relacionado con un relevo generacional y también con la presencia de las nuevas escritoras africanas en el cosmopolitismo, la globalización, la diáspora y en las redes sociales. En un primer momento, las temáticas narrativas mostraban y denunciaban situaciones de dominación colonial pero también las contradicciones, valores y tradiciones africanas que soportaban las mujeres y que, paulatinamente están teniendo que gestionar para adaptar costumbres locales y globales.

Desde estos primeros años ochenta hasta hoy, las mujeres escriben para narrarse a sí mismas. El peso de esta escritura de autorrepresentación debe entenderse, o así nos parece, como una forma de emancipación, como una manera de desnudar el subconsciente, como una subversión de lo doméstico, del cuerpo no normativo, que ayuda a expresar temas como la violencia, el incesto, los feminicidios o los matrimonios forzados. Una literatura que intenta despojarse de connotaciones patriarcales y colonialismos aristocráticos, del apartheid, de segregacionismo con un fuerte contenido crítico y reivindicativo de la cultura africana. No en vano, muchas de ellas están trabajando en medio de la denominada cuarta ola del feminismo, caracterizada por el empleo masivo de las redes sociales como herramienta de in- 
formación y concienciación y como un dispositivo altamente combativo con todas las formas de acoso y sexismo.

Las escritoras africanas, con identidades híbridas, están actualmente construyendo puentes de transconexiones culturales que ayudan a resignificar a África. Un concepto que ayuda a ahondar en este sentido es el de "afropolitismo», que ha acuñado Taidye Selasi y que expresa la idea de escribir desde África para el mundo evitando el exotismo, los clichés folklóricos y costumbristas, y mostrando las particularidades de cada país con una visión global. El espacio literario que las mujeres africanas están aportando se amplía a temas globales como el cómic o la ciencia ficción, que no solo combinan, sino que amplían los textos autobiográficos, las ficciones, las imágenes poéticas, las iconografías, las simbologías y las mitologías africanas.

\section{V}

Y si hablamos de recorridos mitológicos y entendemos que todas las ideologías demandan mitos que legitimen sus relatos, el artículo de Larisa Pérez, titulado «De Fanon a la interseccionalidad: neurosis, sexo y descolonización", lejos de manifestar un momento privado de mitologías nos muestra cómo es necesario activarlas y resignificarlas para dotar de contenido explicativo a las teorías de descolonización. La autora, en una actitud para nada elusiva y escurridiza, nos plantea preguntas y nos propone respuestas aportando a su reflexión planteamientos profundos de la teoría crítica, del feminismo y del postcolonialismo. Estudia cómo la opresión colonialista funciona relacionando la raza y el sexo como dos líneas de subordinación jerárquica y como instrumento básico de la clasificación de la población. Bajo la cobertura de una figura teórica-talismán como es Fanon, y su condición de psiquiatra y su propia versión biografía de entender la identidad de ser negro y hombre desde la zona del no-ser, Larisa Pérez analiza bajo el giro fanoniano lo que denomina «anticolonialismo viril» junto con la engenerización presente en los nuevos feminismos LGTB, apuntando la posibilidad de una interseccionalidad flexible que haga tambalear la colonialidad presente en lo postcolonial y en los feminismos. Teniendo en cuenta lo que plantean las teorías descoloniales, cuando afirman que el postcolonialismo como proyecto epistemológico sigue reproduciendo una forma particular de colonialidad, como dos caras de un mismo proceso (Fanon, 1961; Quijano, 2000). Por lo tanto, desde este punto de vista, la perspectiva descolonial se centra en buscar un canon de pensamiento más amplio que permita mostrar en toda su dialéctica las ideas epistémicas de los pensadores críticos del sur.

Con una alta carga conceptual nos facilita, por un lado, la comprensión de términos a veces ya muy manidos por su capacidad para no mostrarse imparciales. Y, por otro, el efecto devastador del empeño colonizador de mantener una teoría del pensamiento único y totalizado que se concibe externo y se pretende objetivo, pero, al que en realidad no le interesan otros discursos y palabras que evoquen tradiciones, identidades, sexualidades y cuerpos que se sitúen fuera de su alcance cognoscitivo. Un conocimiento empaquetado, como apunta un autor de la teoría descolonial 
como Grosfoguel (2006), que fue capitalista, europeo, militar, cristiano, patriarcal, blanco, heterosexual y masculino. Asimismo, la antropología ha enfatizado cómo los análisis eurocéntricos no son ya una opción científica desde que la independencia de los países colonizados y la globalización permitieran que «los otros», los primitivos, los subalternos, los marginados, los abyectos, etc., emergieran como protagonistas y que se estudiaran ellos mismos. Justamente, cuando «el otro» no necesitó al europeo para narrarse, Occidente perdió la hegemonía del discurso alterándose el eje del discurso único, de una historia oficial que utilizó el primitivismo y el exotismo como políticas de no reconocimiento de las culturas no occidentales.

Desde distintas perspectivas de la teoría social, el postcolonialismo e incluso el arte se han impugnado todos los dispositivos de las representaciones de las culturas no occidentales y de las mujeres que están contenidas en los artículos de este monográfico. Ahora bien, las políticas de representación de los «otros» forman parte, aunque bajo nuevos formatos, de los presupuestos básicos del colonialismo. Como plantea Said (2002), una estrategia de dominación es la orientalización o exotización del sujeto colonial a través de la dicotomía Occidente-Oriente de la que derivan las oposiciones binarias civilizado-salvaje, racional-irracional, maduro-infantil o normal-monstruoso. Otra estrategia es la universalización y normalización de las categorías del conocimiento producidas por Occidente frente a la invisibilización del conocimiento producido por «los otros». Ambas estrategias siguen estando en los constructos epistémicos de las ciencias sociales y en los feminismos mainstreaning occidentales y son a la par formas de un colonialismo que, más allá de contar la realidad, la construye.

Este texto de Larisa Pérez nos demuestra además cómo funcionan las relaciones entre colonizador y colonizado y las ficciones que la raza y la sexualidad han provocado en la patologización de las mismas. No olvidemos que en cualquier contexto, incluido el antillano, al que pertenece Fanon, dominación y subordinación son procesos que desbordan los límites de una sencilla oposición. Ambas engendran una compleja y densa red de relaciones en la cual la resistencia del colonizado puede ser sustituida por la negociación, la pasividad sumisa o la actitud complaciente. Fanon, en este contexto, denuncia el uso del término «negro" y reflexiona sobre la imposibilidad de crear una subjetividad en medio del desprecio social y la centralidad que tiene el lenguaje para la misma. Raza y sexualidad intensifican una doble discriminación que afecta a las mujeres negras a través de su autodesprecio y al hombre negro a través de un supuesto impulso de homosexualidad reprimida. En relación con esto, el énfasis en el feminismo transnacional ha exigido que los críticos culturales presten atención a las formas en las que las políticas de género están modeladas no solo por procesos locales sino también por los globales. Es revelador cómo la autora destila estos análisis sobre colonialidad, postcolonialidad, descolonialidad, sexualidad, raza e interseccionalidad como fuerzas, podríamos decir, «tramposas» en el sentido de que enmascaran todavía la posibilidad de encontrar formas de conocimientos y maneras de nombrar, que permitan ver las contradicciones y esa doble negación de que todo es más complicado de lo que parece ser y uno piensa que es. 
Resulta interesante constatar cómo, dentro de un imperialismo heterosexual que ha caracterizado a la sociedad occidental y desde la literatura, podemos plantear debates sobre la masculinidad no hegemónica. Es lo que hace José Antonio Ramos en el artículo «Los armarios del primer franquismo: el diario del poeta Juan Bernier». El autor nos descubre a un poeta, Juan Bernier, que se ha mostrado como un personaje clave para teorizar sobre la teoría queer. La represión sufrida por los homosexuales, en la primera etapa de la posguerra española, es analizada a través del diario del poeta, miembro del grupo Cántico. Parte del interés de este diario, que de manera magistral contextualiza y desgrana José Antonio Ramos, es que funciona como una declaración abierta del homosexual burgués de provincias que sublima el deseo pederástico, como un testimonio biográfico de la homosexualidad masculina. Cuestión resaltable, teniendo en cuenta que la homosexualidad en el contexto de la dictadura franquista formaba parte de los manuales de patologías y trastornos mentales. Durante mucho tiempo los dispositivos médicos que controlaban y disciplinaban los cuerpos fueron los que otorgaban a los propios sujetos las únicas categorías de nominación posibles según el esquema binario de género.

El planteamiento que contienen las declaraciones del poeta, podríamos decir que posee una finalidad transgresora desde la intimidad. El diario funciona como un espacio expresivo de la adaptación de una identidad y como una plataforma privada de demanda de reconocimiento. Es aquí, desde mi punto de vista, donde reside la originalidad del texto de José Antonio Ramos. Realiza, de manera exhaustiva, un análisis de la variedad de formas en las que se podría expresar la orientación sexual del poeta en una época tan turbulenta y tan poco tolerante. En el texto se hace un juicioso desarrollo de la literatura diarística europea que permite contextualizar la opresión y la persecución sobre cuerpos considerados como «invertidos», "guayabos», «maricas», "plumas», "afeminados» o "lobas», y también reconocer influencias literarias como realizar taxonomías de los personajes y los placeres prohibidos. Además, se identifican y cuestionan la política sexual, las formas de organización de género y la sexualidad en el espacio sociopolítico español.

En mi lectura del texto, quisiera destacar la manera provocativa de explorar los presupuestos básicos que caracterizaban la homosexualidad masculina en la época: el aislamiento, la invisibilidad y los procesos autoimpuestos de normalización y el cruising. Todo ello junto con los objetivos conservadores que defienden a ultranza la familia, la tradición, la religión, la propiedad y, por supuesto, la heteronormatividad como un fundamento trascendental del orden social. Ya para entonces, los jardines, los billares, los baños públicos e incluso las iglesias forman parte del espacio homosexual masculino. Y cobran su importancia como ubicaciones heterotópicas, como espacios de la diferencia. En términos de Foucault, como espacios en los que las relaciones entre los elementos quedan suspendidas, neutralizadas o revertidas. De otra manera, los espacios periféricos de las provincias operaban como una crítica a la propia sociedad heterosexual. Podemos entenderlos como metáforas espaciales y simbólicas que acogen a las sexualidades no heteronormativas y que constituyen el núcleo de la homosociabilidad. 
Asimismo, el diario resulta clave para analizar, por ejemplo, los roles que desempeñan los homosexuales masculinos entre ellos, el tema del autoengaño, los compromisos sociales y los subterfugios de sus prácticas cotidianas. No menos importante es entender que la peor parte de la homosexualidad masculina es tener que mantenerlo en secreto. Una especie de violencia interna que les impone la sociedad heterosexual. Bajo estos parámetros, vivir «armarizado» es consecuencia del sometimiento a una sociedad franquista en la que no era posible que un yo homosexual se pudiera expresar y narrar sin ningún tipo de censura. Así, pues, incuestionablemente el concepto del armario (out of the closet) como un tópico de los estudios gay-lésbicos, según Kosofsky (1998), se erige como relevante para definir la opresión homofóbica. La posición de estar dentro o fuera del armario se identifica con la necesidad de mantener en secreto la orientación sexual o desvelarla. El aislamiento que produce la "armarización» conduce a aceptar las prácticas del deseo como una opresión y vergüenza.

$Y$ es en este momento cuando el diario autobiográfico o autoficticio del poeta, no me queda muy claro, se coloca de manera privilegiada para analizarlo desde el enfoque de los estudios shame gay, como una manera perpiscaz de seguir indagando, repensando, cuestionando y arrojando luz sobre el tema de la homosexualidad masculina. Una posición desde la que se cuestiona el orgullo gay, como una quimera neoliberal consumista de un supuesto lobby homosexual. Un homosexual avergonzado se construye frente a un homosexual orgulloso. Quizás, pareciera que estuviéramos enfrentándonos a una reconstrucción, otra vez más, de uno de los clichés coloniales que definiría y equipararía lo civilizado con el orgullo y lo salvaje con la vergüenza.

\section{VII}

Dentro de las investigaciones noveles, se incluyen dos trabajos. El primero, de Alejandro Domingo Hernández, titulado «Percepciones de las personas transexuales sobre su integración social»; y un segundo, de Sara Rozenwajn, titulado «Género, cuerpos y deporte: una aproximación al contexto profesional». En el primero, el autor realiza un trabajo de campo sobre los procesos de integración social, laboral y sanitaria de las personas transexuales en la Comunidad Autónoma Canaria, que tal y como se expone no dista mucho de otras comunidades, países europeos y norteamericanos. Para ello, contempla las leyes de asistencia a las personas transexuales y plantea la situación de vulnerabilidad de este colectivo, que demanda plataformas críticas de reconocimiento. La realidad se encarga de desmontar la legislación específica en transexualidad (trabajo, sanidad, cirugías, documentación oficial, usos de espacios como baños y vestuarios) que desde 2014 está establecida en Canarias.

Una de las ideas que se deslizan del trabajo es que las condiciones y diferencias de oportunidades vitales de las personas transexuales influyen directamente en las condiciones de marginalidad a las que están expuestas. Yo diría que, en gran medida, porque muchos aspectos de sus vidas están supeditados al control directo de los organismos jurídicos y administrativos, que, por otra parte, están constitui- 
dos históricamente bajo un esquema heteronormativo centrado en un binarismo de género rígido.

Todo este sistema tiende a dificultar especialmente la obtención de recursos, restringe el acceso a espacios de protección y empoderamiento de las personas transexuales y hace que la pérdida de empleo, rechazo social, asistencia sanitaria, etc., sea más difícil y costosa. Cuando las personas transexuales no pueden cubrir sus necesidades por razones económicas, administrativas o jurídicas, se convierten en cuerpos indescifrables para la sociedad que los rechaza. Es decir, en personas con cuerpos no normativos, abyectos para un sistema encargado de vigilar, gestionar y controlar a esta población que no tiene nada que ganar del statu quo.

Para las personas transexuales, esta dominación se intensifica cuando deciden operarse para modificar sus genitales y convertirse en hombres o mujeres perfectamente legibles públicamente. Los transexuales se ven condicionados por el propio binarismo sexual, viéndose expuestos a intervenciones quirúrgicas como la vaginoplastia y la faloplastia. Aquí radica una diferencia sustancial entre los transexuales y los transgéneros. Estos últimos movimientos, a diferencia de los primeros, quieren desmarcarse de las connotaciones médicas y patologizadoras de la transexualidad, y del recurso a la cirugía como una manera estereotipada de géneros basada en la coherencia entre género y aspecto genital, que no hacen sino reproducir las identidades de género masculinas y femeninas estándar. Ya Butler planteó este escenario de resistencia contra el dispositivo de la sexualidad y la dislocación de las normas de género dictadas por la matrix heterosexual al hacernos partícipes del concepto de performatividad.

El artículo de Alejandro Domingo Hernández es una buena oportunidad para profundizar en la profusión de identidades de género que caracterizan a las sociedades en el siglo xxi y que tienen en común un compromiso político de romper con los ideales binarios. Como ha demostrado Paul Preciado (2014), esta profusión de identidades también puede ubicarse dentro de los sistemas biomédicos y farmacéuticos de manipulación y control corporal. Los régimenes farmacopornográficos de gestión del deseo y de la identidad proponen que términos como masculinidad, feminidad, heterosexualidad, homosexualidad, transexualidad o trangenerismo han ido perdiendo su sentido en paralelo con el progreso farmacéutico (viagra, hormonas, contraceptivos, drogas recreativas, analgésicos, antidepresivos, somníferos, suplementos antiedad, etc.) que reconfiguran la identidad corporal por medio de intervenciones moleculares y químicas, en vez de basarse en nociones de salud física o psicológica. También Braidotti (2015), en sus ensayos sobre lo posthumano, introduce una visión renovadora a la discusión con la categoría de "zoepolítica poshumana», con la que describe un presente en el cual el capitalismo biogenético gobierna no solo la vida de la especie humana, sino también el código genético de la vida misma, no limitándose ya a regular a los seres humanos como individuos liberales, sino tratándolos como dividuos biogenéticos, portadores de informaciones vitales.

En el segundo texto, "Género, cuerpos y deporte: una aproximación al contexto profesional», Sara Rozenwajn, explora las relaciones entre género, cuerpo y deporte en la construcción identitaria y en los discursos que funcionan en torno a ella. Su trabajo podemos entenderlo como una manera de poner en debate las 
segregaciones de género en el ámbito de una práctica social como el deporte, que se ha convertido en un mecanismo estratégico económica, política y culturalmente para cualquier país capitalista y democrático, que lo utiliza como una herramienta fundamental para legitimar la educación, la salud, el desarrollo e incluso la paz como postula la UNESCO o un motor de cambio mundial como consideraba Mandela.

La autora se encarga de mostrar cómo los medios de comunicación, la industria, la publicidad o Internet refuerzan los estereotipos de género discriminando a las mujeres en los premios deportivos como, por ejemplo, pasa entre las mujeres boxeadoras y surfistas. Esta práctica androcéntrica contribuye a normalizar la desigualdad de género en el deporte y a hipersexualizar a las mujeres. En este sentido, no quiero pasar por alto los prejuicios sexistas presentes en la prensa deportiva y en los espacios de información deportiva. La participación de las mujeres en las Olimpiadas de Río de 2016 no solo ocupó tres veces menos espacio informativo que los hombres, sino que además los titulares fueron auténticas vejaciones y agresiones contra las mujeres («Lydia Valentín, una Hercúles con maquillaje», $A B C /$ «La lista de buenorras internacionales en los Juegos Olímpicos de Río», El Mundo. Tras las críticas de este titular lo cambiaron por "Las atletas olímpicamente atractivas» / «Las seis deportistas más sexys de los Juegos Olímpicos de Río de Janeiro", El Mundo Deportivo / "Hosszu, la nadadora que batía récord mundial "gracias a su marido"», Cadena NBC).

Creo que este modus operandi explicaría por qué a pesar de que el deporte ofrece numerosos ejemplos de grandes triunfos femeninos sus gestas y logros parecen siempre por detrás de los que consiguen los hombres deportistas. Hay un ejemplo que me parece paradigmático. La tenista Serena Williams atesora 23 títulos de Grand Slam. Más que Roger Federer, que posee 20, y que Rafael Nadal, que tiene en sus vitrinas 17, y que Novak Djokovic, con 14. A pesar de ello, los tres ases masculinos han ganado mucho más dinero que ella. Estas diferencias de ingresos entre hombres y mujeres en el deporte de élite se convierten en desigualdad de oportunidades en las categorías inferiores. Lo que demuestra que el triunfo deportivo tiene un precio insostenible y es mucho más exigente con las mujeres. Pero también a nivel cultural, por ejemplo, en muy pocas ocasiones se refuerzan y se muestran las mujeres referentes del mundo femenino, a diferencia de los hombres, ávidos siempre de hacer desfilar a sus ancestros deportivos. Los datos de trabajos de la antropología del deporte reflejan que existen importantes diferencias en cuanto a la participación deportiva y la gestión de eventos por parte de mujeres y hombres (Saavedra, 2009; Besnier; Brownell; Carter, 2018). Lo que demuestra la brecha de género en la práctica y en la gestión del deporte.

Por otro lado, Sara Rozenwajn manifiesta que en contra de estos tópicos, las mujeres practican más deportes considerados masculinos que hombres que realizan deportes considerados femeninos, ante los cuales se muestran más reticentes. Considero que esta realidad objetiva está muy relacionada con el hecho de que el sistema deportivo se pensó para los varones en pleno desarrollo de la industrialización. Las mujeres quedaron fuera tanto de sus prácticas como del disfrute como espectáculo y ocio. El mecanismo ideológico fundamental para excluir a las mujeres se basó en la idea de que la propia naturaleza humana dotaba a los seres de capacidades diferentes 
y, por supuesto, el sexo femenino por naturaleza no estaba preparado para lo público. A partir de aquí se ideologizaron y se mitificaron ideas como que las mujeres no están interesadas en el deporte, el deporte masculiniza a las mujeres, el deporte es peligroso para la salud de las mujeres, no se les da bien la práctica deportiva. Todas estas razones han influido para prohibir o reducir la participación de las mujeres en competiciones y eventos deportivos. Por otro, desde mi punto de vista, podemos tomar en consideración el concepto de Teresa de Lauretis de "tecnologías de género» (2000) para estudiar, desde una perspectiva feminista, el fenómeno deportivo. El deporte, al igual que el cine, el arte o la ciencia, funciona como un espacio de exclusión, discriminación y segregación de género. Esto ayuda a entender por qué el deporte ha sido y sigue siendo un coto donde los hombres construyen su masculinidad dentro de un proceso de exclusión sexuado donde las prácticas disciplinarias corporales y las identidades sexuales se representan como modelos sociales del género. Después de lo que hemos dicho, la cuestión está en no caer en el error de pensar que las identidades sexuales son algo fijo, estable y coherente. Además, la propia flexibilidad de las mismas supone una amenaza de desestabilización constante que deja a los cuerpos, al género y al poder rápidamente obsoletos, arruinando cualquier expectativa de conseguir una forma unificada e invariable de las identidades sexuales. 


\section{BIBLIOGRAFÍA}

BaIn, A.L. (2004). «Female artistic identity in place: the studio». Social \& Cultural Geography, 5(2), pp. 171-193.

BaIn, A.L. (2005). "Constructing an artistic identity. Work Employment \& Society 19(1), pp. 25-46.

BAIN, A.L. (2007). "Claiming and controlling space: combining heterosexual fatherhood with artistic practice». Gender, Place and Culture 14(3), pp. 249-265.

Braidotti, R. (2015). Lo posthumano. Barcelona: Gedisa.

Besnier, N., Brownell, S. y Carter, Th. (2018). The Anthropology of Sport: Bodies, Borders, Biopolitics. California: University of California Press.

CÉSAIre, A. (2006). Discurso sobre el colonialismo. Madrid: Akal.

De Lauretis, T. (2000). Diferencias. Etapas de un camino a través del feminismo. Madrid: horas y HORAS.

FAnon, F. (2001). Los condenados de la tierra. México: FCE.

Femen (2014). En el principio era el cuerpo. Barcelona: Malpaso Ediciones.

Grosfoguel, R. (2006). «Decolonizing Political-Economy and Post-Colonial Studies: Transmodernity, Border Thinking, and Global Coloniality». Tabula Rasa, n. ${ }^{\circ}$ 4, pp. 17-48.

Halberstam, J. (2018). El arte queer del fracaso. Barcelona: Egales.

Haraway, D.J. (1995). Ciencia, ciborgs y mujeres. La reinvención de la naturaleza. Madrid: Ediciones Cátedra.

Kosofsky, E. (1998). Epistemologías del armario. Barcelona: Ediciones la Tempestad.

Marçal, K. (2017). ¿Quién le hacia la cena a Adam Smith? Barcelona: Debate.

Nixon, S. (2003). Advertising Cultures. Gender, commerce, creativity. London: Sage.

Nochlin, L. (2007). «¿Por qué no han existido grandes artistas mujeres?», en Karen Cordero Reiman e Inda Sáenz (comps.), Critica feminista en la teoría e historia del arte. México: Universidad Iberoamericana/Universidad Nacional Autónoma de México, pp. 17-43.

Pollock, G. (2013). Visión y diferencia. Feminismo, feminidad e historia del arte. Buenos Aires: Fiordo.

Preciado, P. (2014). Testo yonqui: sexo, drogas y biopolitica en la era de la farmacopornografía. Barcelona: Paidós.

Quijano, A. (2000). «Colonialidad del poder y clasificación social».Journal of World-Systems Research, vol. XI, núm. 2, Summer/Fall, pp. 342-386.

SaAvedra, M. (2009). "Dilemmas and Oportunities in Gender and Sport-in-Development», en R. Levermore \& A. Beacom (eds.), Sport and International Develoment Global Culture and Sport. London: Palgrave Macmillan, pp. 124-155.

SAID, E. (2002). Orientalismo. Madrid: Debate.

Turner, V. (1974) Dramas, Fields and Metaphors. Symbolic Action in Human Society. Ithaca and London: Cornell University Press. 